\title{
Reflections on the revolutionary wave in 2011
}

\author{
Colin J. Beck
}

Published online: 6 February 2014

(C) Springer Science+Business Media Dordrecht 2014

\begin{abstract}
The "Arab Spring" was a surprising event not just because predicting revolutions is a difficult task, but because current theories of revolution are ill equipped to explain revolutionary waves where interactive causal mechanisms at different levels of analysis and interactions between the units of analysis predominate. To account for such dynamics, a multidimensional social science of revolution is required. Accordingly, a meta-framework for revolutionary theory that combines multiple levels of analysis, multiple units of analysis, and their interactions is offered. A structured example of theory building is then given by detailing how the development of world cultural models and practices challenge existing political structures, affect mobilization processes, and make diffusion more likely. A structured example of study design using qualitative comparative analysis of 16 Middle Eastern and North African countries provides support for the interaction of subnational conditions for mobilization, statecentered causes, and transnational factors, including a country's linkage to world society, as one explanation of the Revolutions of 2011.
\end{abstract}

Keywords Revolution · Arab spring · World culture - World society · Arab countries

On January 14, 2011, the long time dictator of Tunisia, Ben Ali, fled Tunis after his military chief refused to suppress a month long popular protest against autocratic rule and corruption. Shortly thereafter, Egyptian activists launched the beginning of protests that would lead to the resignation of Hosni Mubarak, protestors occupied central squares in the capitals of Bahrain and Yemen, and Libyan and Syrian demonstrations, which later devolved into civil war, began. By March, nearly the entire Arab World, and even elsewhere, had experienced contention that almost no one seemed to anticipate. The surprising "Arab Spring” or, as I and other scholars (e.g., Goldstone 2011) might prefer it, the "Revolutions of 2011 " had arrived.

While many scholars of revolution would not be astonished that prediction of these events had failed (see Keddie 1995; Kuran 1995; Kurzman 2004), the New York Times reported that President Obama faulted American intelligence agencies for not expecting the revolutions (Mazzetti 2011), and a Middle East scholar faulted his own discipline

C. J. Beck $(\bowtie)$

Department of Sociology, Pomona College, 420 N. Harvard Avenue, Claremont, CA 91711, USA

e-mail: cbeck@pomona.edu 
for being too narrowly focused on the persistent stability of the region's regimes (Gause 2011). But the Revolutions of 2011 should be considered surprising for another reason beyond their sudden emergence. This was a revolutionary wave, and such waves encompass, by definition, multiple states and societies and are inherently transnational. Yet predominant explanations of revolution are generally focused on dynamics within a singular state and society, and they are thus not well suited to explaining transnational dimensions and the spread of contention. Theoretically and methodologically, the social science of revolution displays what Beck (2002) calls "methodological nationalism," where the global and regional embeddedness of societies and their interactions are rarely accounted for systematically.

I argue that a solution to this lacuna lies in multidimensional theorization of revolution. If revolutions are rare events because seldom do all the necessary conditions correspond (Foran 1993; Goldstone 2001, 2011), then the task is to explain explicitly the correspondence of factors rather than to add merely new causes and mechanisms to the model. Whereas prior generations of theories of revolution emphasized state and movement level processes, future revolutionary theory should explicitly account for processes across transnational, national, and subnational levels of analysis. Further, revolutionary waves should be placed in the center of revolutionary theory and study as the most transformative revolutions - and in the modern era, even most revolutions generally_occur in waves (Beck 2011; Goodwin 2001; Mann 2012, 2013; Tilly 1993). I thus develop a meta-framework for understanding revolution across multiple interactive levels and units of analysis in the first part of this article.

In the second part, I provide a structured example of theory building and study design using the case of the Revolutions of 2011. I illustrate how a multidimensional theory can be built to explain this wave by emphasizing the role of world culture in revolution. I argue that the growth and institutionalization of world cultural models delegitimates regimes that are incongruent with prescribed forms and practices, creates subnational actors that are empowered symbolically and practically to challenge states, and intensifies the processes that allow for contention to diffuse from its initial site. Prior research on transnational cultural conditions has found them to be important for understanding generally when and why revolutions take place (Halliday 1999; Sharman 2003). When combined with prior explanations of state breakdown and revolutionary mobilization, a fuller explanation of revolution and revolutionary waves is at hand. Thus, in the final section, I provide an example of how a multidimensional investigation of revolution can be undertaken using qualitative comparative analysis of the conditions and outcomes of 16 Middle Eastern and North African countries during the Revolutions of 2011. The results suggest a clear role for transnational dynamics in interaction with state and subnational factors, including a country's embeddedness in world society.

The goal here is to provide a framework for theorization of revolution that is inclusive and analytically useful rather than merely advocating a particular mechanism. While the structured examples of theory building and study design show how this can be done, I make no claims that world culture is the sole path for multidimensional theorization nor that the Revolutions of 2011 are entirely explained by the interactive mechanisms considered. I first begin by briefly reviewing revolutionary theory, discussing its theoretical and methodological focus on nationally-centered cases, which downplays multidimensional logic and transnational factors. 


\section{Case-centered theory and its discontents}

Over the last century, scholarship on revolutions has gone through four primary generations (Goldstone 2001). With each generational shift, the primary focus of revolutionary theory has oscillated between primarily structural conditions, often state-centered, and subnational dynamics of and conditions for mobilization. Specifically, the early twentieth-century natural history of common stages and national conditions (e.g., Brinton [1938] 1965; Merriman [1938] 1963; Pettee 1938) was replaced by post-World War II aggregate social-psychological models of mobilization (e.g., Davies 1962; Huntington 1968; Johnson 1966). The third generation's statecentered theory again placed structure at the fore, primarily through state breakdown generated by administrative strain and elite schisms (Skocpol 1979; Goldstone 1991; Goodwin and Skocpol 1989; Goodwin 2001; Tilly 1978). Structure was again replaced by mobilization with the "cultural turn" in social science, where the center of attention became culture and ideology (e.g., Parsa 2000; Sewell 1985; Sharman 2003), individual perceptions, judgments, and agency (e.g., Kuran 1995; Kurzman 1996; Selbin 1993; Sohrabi 2002), and issues of identity, solidarity, and marginalization (e.g., Gould 1995; Moghadam 1997; Reed and Foran 2002; Viterna 2006; Wickham-Crowley 1992).

Yet each generation of revolution theory mostly left the problems of revolutionary waves and transnational dimensions aside. This is particularly remarkable as many scholars of revolution have noted that not only do revolutions tend to come in waves across many societies (e.g., Brinton [1938] 1965; Palmer 1959; Goldstone 1991, 2001; Katz 1997; Markoff 1996; Mann 2012; Tarrow 1993), but that increasingly over the last two centuries the proportion of revolutions that occurs in waves has grown (Beck 2011; Goodwin 2001; Mann 2013; Tilly 1993). Theoretically, placing the state or regime (as the first and third generation do) or the subnational dynamics of mobilization of social groups and individuals (as the second and fourth generation do) at the center of revolutions focuses attention within the boundaries of one society. Methodologically, state and movement level approaches have preferred studies of singular events or the comparison of national cases, obscuring international and transnational dynamics.

This is not to say that consideration of conditions exogenous to nation-states has never occurred. Some theories of revolution include international factors as modifiers to otherwise state-centered causes of revolution. For instance, a few scholars historicize revolution by placing it in a supra-state political opportunity structure: the existence of external threats and war (Skocpol 1979; Mann 2013; Walt 1996) and templates of revolutionary mobilization (Sohrabi 1995; Halliday 1999). Further, there were also third generation attempts to combine the state autonomy perspective with world systems analysis and global economic dependency (e.g., Farhi 1990; Foran and Goodwin 1993; Goldfrank 1979; Walton 1984). In both instances, however, the state remains the central focus of analysis.

Other syntheses of revolution theory have tried in various fashions to grapple with the conjunction of multiple levels of analysis. For instance, Kimmel's (1990) critique of the insufficiency of Marxist, state-centered, and world systemic theories of revolution concludes with a call for research that places states within their international arenas, takes class analysis seriously, and considers the context of time and space. Halliday's (1999) essay on the occlusion of revolution from international relations theory 
combines an actor-centric account of transnational ideologies with the intentional export of contention from post-revolutionary states, charting the domestic and international processes that operate during different stages of revolution. More recently, Mann (2013) asserts forcefully that most twentieth century revolutions are the product of class struggle combined with an authoritarian's defeat in war (or a personalist regime) that then has macro-regional effects on revolutionary attempts elsewhere. These syntheses have two commonalities. First, they tend to privilege a particular set of causes and mechanisms rather than a more general framework for including transnational explanations of revolution. Second, even when revolutionary waves are noted, the conditions and limits of their spread tend to be taken as historical facts rather than objects for theorization and study. Perhaps these are the reasons why transnational conditions and revolutionary waves never became a paradigmatic concern.

From prior perspectives, a transnational revolutionary wave is thus quite a puzzle. We see some of these limitations in trying to explain the Revolutions of 2011 with third and fourth generation approaches. Certainly, Arab regimes tend to take the exclusionary forms that third generation scholars have found to be susceptible to challenges from below, and many of the states affected have been under increasing strain as economic fortunes change and populations grow. Many Middle Eastern societies also have a number of the factors that have been theorized by fourth generation theorists to fuel revolution, such as disaffected marginal elites and populaces, legacies of rebellion, and social and organizational bases for mobilization. Yet not one of these factors explains how it is that protest spread so quickly and so far, affecting regimes that heretofore appeared to have an iron grasp on power (such as Qaddafi's Libya) or with little history and experience of mobilization against the state (such as Tunisia). Satisfactory explanation requires something more.

Few nations are islands. Rather, states and societies are embedded in regional, international, and global frameworks and relationships, and revolutionary waves (and indeed, even singular revolutions) are transnational events (Halliday 1999; Lawson 2005). Attention to these supra-national dynamics has typified the modest amount of research on revolutionary waves that does exist. One approach has been to emphasize that the same pressures can create near simultaneous revolutions and hence a revolutionary wave (e.g., Goldstone 1991). These causes may be products of the transnational system itself, for instance: the growth of new global economic forms (e.g., Paige 1975; Wallerstein 1980); the occurrence of global anti-systemic movements (e.g., Arrighi et al. 1989); cycles of hegemonic power (e.g., Boswell 2004); or changes in models of revolution (e.g., Sewell 1985; Sharman 2003; Sohrabi 1995). A second perspective stresses cross-national diffusion mechanisms that culminate in a cycle of protest, emphasizing the role of actors in exporting and adopting tactics (Beissinger 2007; Katz 1997; Markoff 1996; Tarrow 1993; Weyland 2009). Yet transnational conditions and diffusion processes by themselves have trouble explaining the full range of contention seen in revolutionary waves. For example, all Arab countries presumably existed as part of the same global system in 2011 and so it is unclear why potential protestors would adopt a tactic in some places and not others. And a point-to-point diffusion theory cannot tell us why protest turned into revolution in Egypt, civil war in Syria, conciliation in Jordan, and the status quo in Algeria. Just as case-centered theory alone cannot well account for a revolutionary wave, wave-centered theory alone cannot tell us how individual revolutions will occur. 
2011 , or indeed $1789,1848,1917$, or 1989 , suggests that it is high time to escape methodological and theoretical nationalism by developing a "methodological cosmopolitanism” (Beck and Sznaider 2006). Transnational revolutionary waves, occurring across multiple and interactive levels, should be placed at the center of revolution studies. The most fruitful path for theory and study begins by understanding what needs to be explained in the first place.

\section{A multidimensional framework for revolutionary theory}

Although some scholars (e.g., Goldstone 1991; Goodwin 2001) have argued that statecentered factors are the most parsimonious explanation of revolution, recent work has emphasized other mechanisms in the revolutionary process. For instance, interactions among levels of analysis (Lawson 2005) and the environmental contexts of mobilizing processes (Emirbayer and Goodwin 1996) have each received some attention. In the study of movements more broadly, McAdam et al. (2001) influentially call for work that recognizes a multiplicity of interactive, relational mechanisms reoccurring across cases.

This creates a dilemma for the theorist of revolution-if the clean models of parsimonious explanation are to be rejected in favor of the dirty hands of mechanistic perspectives, how can a theory of revolution be built? The answer is to strike a balance between contextual inclusion and abstract parsimony through a programmatic fusion of prior work. In this way, knowledge accumulation will emerge from ongoing theorization rather than repeated waits on new events to test for congruence or oscillating generational debates (see Goldstone 2003). I argue that this can and should be more than just another theory of revolution, if a simple axiom is kept in mind:

Meta-axiom: Revolutions take place across multiple levels of analysis (i.e.,. subnational, state, and transnational), multiple cases of the units of analysis (whether individuals, groups, movements, regimes, societies, or states systems), and through interactions of levels and the units.

This axiom stresses the notion of the multidimensionality of revolution, whether we call it cosmopolitanism, conjunctural logic, or relational mechanisms. From this starting point, three meta-theorems are implied:

Meta-theorem ${ }_{1}$ : Revolutionary theory must develop accounts of each level of analysis, including the transnational, the state, and the subnational.

Meta-theorem ${ }_{2}$ : Revolutionary theory must develop accounts of how levels of analysis interact with each other, i.e., transnational-state interactions, transnational-subnational interactions, and state-subnational interactions.

Meta-theorem 3 : Revolutionary theory must develop accounts of how units of analysis interact with each other.

The framework highlights the need for theorization across all possible dimensions with a focus on conjoint causation. Thus, the emphasis is on the need for both relational 
perspectives on mobilization, e.g., movement-countermovement dynamics, and states, e.g., international diffusion. This provides a way to bring the study of revolutionary waves back in to the study of revolution.

The meta-framework is deliberately agnostic on the question of the timing of revolutions. When revolutions exactly occur is a crucial issue for prediction of future revolutionary events (Keddie 1995) but is less helpful for explanations that consider causal conditions and mechanisms with long time horizons. In fact, a focus on timing can presuppose that fast-moving outcomes must have fast-moving causes and shackle the development of careful research (Pierson 2003). Further, contingency, random events, and perceptions outside the bounds of any theory can provide the triggers or positive feedback loops that make revolution possible (Kurzman 1996; Mann 2013; Sewell 1996; Weyland 2009). We should certainly celebrate those theories that can meet this challenge. But the question of whether timing is an important aspect of a given theory of revolution is best left to the given theorist of revolution.

Fortunately, there is no need to reinvent the revolutionary wheel entirely, only to furnish its missing spokes. Third generation structural theories of revolution tell us quite a bit about the state-centered conditions that yield revolutionary situations, as well as hint at various transnational factors that can be harnessed. Fourth generation theories not only provide accounts of subnational environments and the mobilization process, but also their interactions with state structures. In truth, much of the framework elucidated by the meta-theorems is already in place. It is primarily the transnational conditions that apply to both revolutions and revolutionary waves that have yet to be systematized and synthesized with prior accounts. Thus, the following principles, derived from the meta-framework, should guide theorization of transnational revolutionary waves:

Principle $_{1}$ : Recognize that states and societies are globally embedded, and thus identify regional, international, and transnational factors that affect the onset and course of revolution.

Principle $_{2}$ : Explain why and how transnational dynamics impact states and create the potential for state breakdown.

Principle $_{3}$ : Explain why and how transnational dynamics have subnational effects and impact contention.

Principle $_{4}$ : Explain why and how the units of analysis - which for transnational factors is often a society - interact, whether through diffusion and the creation of new repertoires or positive feedback loops where the original causal factors are magnified and grow.

In short, a revolutionary theory that incorporates the transnational and can explain waves of revolution might look like the abstract sketch of Fig. 1. Here, transnational dynamics are conceptualized vis-à-vis state-centered factors and subnational processes of contention, and the spread of mobilization across multiple societies is emphasized. Argumentation along these lines accommodates both explanations of revolution and revolutionary waves at once. This contrasts to both single interaction models of 


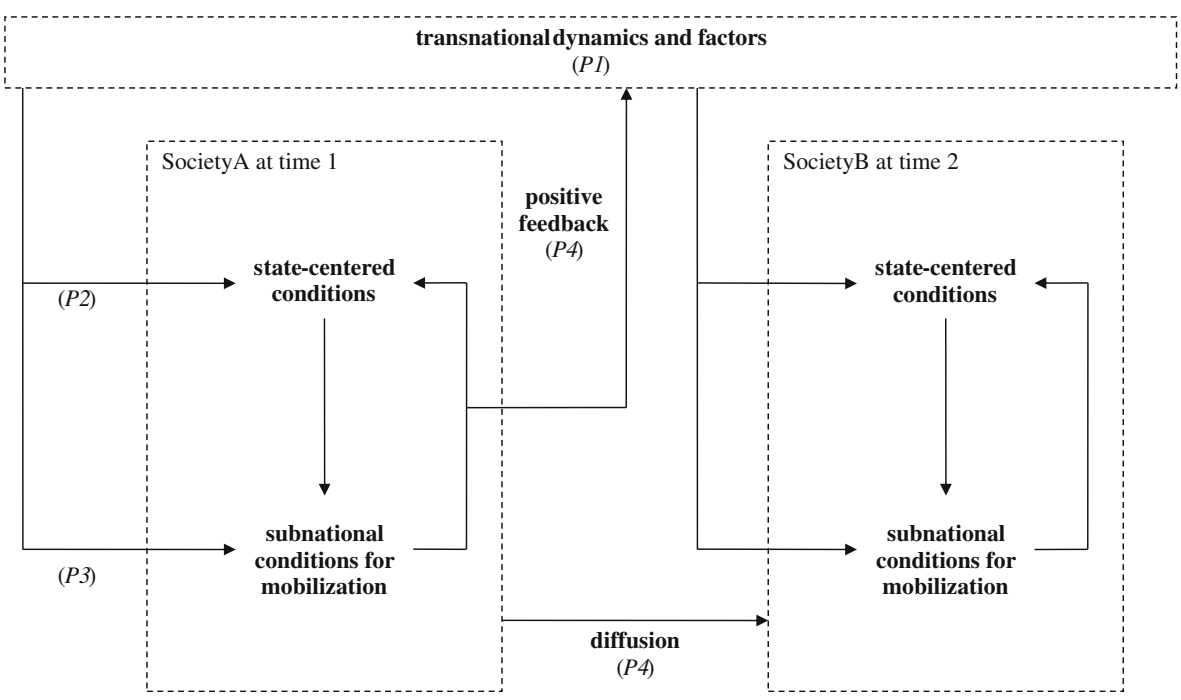

Fig. 1 A framework for transnational and multidimensional revolutionary theory

international influences, e.g., Skocpol's (1979) external threat creating fiscal strain, and presumptions that revolutions spread independent of other conditions, as in Weyland's (2009) rational actor model of diffusion. In short, the model overall is a framework for future social science of revolution. In the next section, I illustrate how such a theory can be built using the example of world culture's interaction with states and societies in the Revolutions of 2011.

\section{Theorizing the Revolutions of 2011}

Two recent studies come close to accomplishing the goal of multidimensionality. Foran's (2005) five factor framework for revolution addresses most of the principles above handily: he theorizes that the international process of dependent development creates the state-centered condition of exclusionary regimes most susceptible to challenges, which in turn gives rise to the subnational mechanism of political cultures of opposition. Revolutions then occur when economic downturn, whether global or national, combines with a political opportunity at the world level. Similarly, Kurzman's (2008) investigation of the democratic revolutions of the early twentieth century also covers much of the needed terrain. While he shies away from offering a grand theory, Kurzman argues that intellectuals in various societies became revolutionary actors as their identity grew and diffused globally, accompanied by a shift towards a transnational ideology of positivist liberalism and democratic ideals. The democratic intelligentsia thus formed the "backbone of prodemocracy movements around the globe" (Kurzman 2008, p. 13), finding allies among other classes in society, elements of regimes, and foreign great powers, even though many democratic transitions faltered.

Both Foran's and Kurzman's studies may stand as the culmination of fourth generation revolutionary theory, and the first theories of a new cosmopolitanism. In broad strokes, we could apply these accounts to the Revolutions of 2011. Many Middle 
Eastern countries are in a situation of dependent development with economies oriented towards the export of oil, agriculture, or other resources to core nations. As Foran would anticipate, regimes have developed that are exclusionary and thus experience recurrent anti-state mobilizations creating cultures of opposition. In 2008, the financial collapse created economic downturn and furthered the decline of American power, creating a political opportunity for mobilization. This is an attractive application, yet it leaves revolutionary waves aside, even though many of the cases Foran considers occurred as part of revolutionary waves themselves. Further, there is no theorization of diffusion and it tells us little about why contention in Tunisia would spread throughout much of the Middle East and North Africa. The theory thus fails a crucial aspect of the proposed framework - the interaction of the units of analysis. Alternatively, we could focus on the growth of educated, urban, and globally connected elites in the Middle East who lacked meaningful political or economic opportunities. Like their early twentieth century predecessors described by Kurzman, these activists imported models of non-violent revolution from other societies, copied one another's mobilizations, built coalitions within and across their societies, and created the spread of revolution across the region. Again, this treatment is believable, but the state is left out and thus not all levels of analysis are accounted for. It seems little coincidence that in 2011, protest culminated in revolution in only those societies with exclusionary regimes and governments' falls were accompanied by intra-regime schisms and the failure of state repression. Holistic explanation requires something more than offered by either account.

I thus offer a view of the Revolutions of 2011 that attempts to address all aspects outlined in the meta-framework by emphasizing the growth of world cultural scripts, models, and practices, and their attendant impacts on states and subnational conditions for mobilization. Prior work on the role of culture and ideology in revolution has emphasized the importance of the legitimacy of political structures, the creation of new forms and rationales of political action, and popular beliefs and ideology of movements and regimes (Sewell 1985; Sharman 2003). It should be clear that transnational models inform these cultural dimensions. Below, I argue that the content and operation of modern world cultural processes challenge states when there is contradiction between the transnational and the local, empower oppositions through the construction of agency and personhood, and intensify diffusion by creating international connections and at least symbolic structural equivalence.

First, the neo-institutional world society perspective emphasizes that states must conform, if only symbolically, to global models or risk losing legitimacy internationally (Meyer et al. 1997; Meyer 2010). But legitimacy is also at risk domestically. State structures that are not in line with what the larger international environment sanctions cannot rely on these larger cultural frames for their legitimation. Thus, regimes in such incongruent states may face a persistent legitimation crisis and struggle to maintain their authority without reliance on naked coercive power. This creates a political opportunity for challenges from inside as well as outside the regime (Beck 2011), and allows for no other way out of crises then revolution (Goodwin 2001). For example, the communist regimes of the Soviet Bloc fought in the 1980s to maintain their popular legitimacy in the face of increasing economic and political strains on their states and as democratic human rights became enshrined in international law and practice. Once coercion was implicitly demonstrated to be ineffective in the face of 
popular collective action (Pfaff 2006) or explicitly ruled out by reformist elements (Lawson 2005), the persistence of the illegitimate regimes was unlikely. In an earlier era, the absolutist monarchies of eighteenth century Europe, such as France, were challenged by growing universalized discourses of natural rights and republican governance (Chartier 1991). In contrast, the constitutional monarchism of the British state, which was relatively more enlightened, was less incongruent with these emergent ideals and more durable in the face of contention. Yet contention against an incongruent state need not always bend in a democratic direction. The Russian Revolution of 1917, for example, targeted one of the few remaining agrarian-bureaucratic states in an increasingly capitalist and industrialized world, but did so with an alternate transnational ideological basis as described below. The key to each of these examples is that the legitimacy of states, and thus their ability to weather challenges to their rule, is not just constructed locally.

In short, contradiction between transnational scripts and local practices can challenge states as much as fiscal crises, international warfare, or world economic cycles. One transnational dimension of revolution can thus be theorized by considering how a state's legitimate order operates and exists in comparison to dominant models of governance. This accounts for the interaction between transnational conditions and state-centered causes of revolution. In the contemporary period, the authoritarian regimes of 2011 in the Middle East were increasingly in contradiction with world models, particularly as other regions like Latin America and Eastern Europe democratized. The American imposition of, at least notionally, a democratic state in Iraq and the success of a relatively liberal Islamic party in Turkey provided a model for how transnational scripts could be adapted locally (as in an earlier era [see Sohrabi 2002]). Thus, authoritarian regimes like Tunisia, Egypt, Libya, and Syria became increasingly delegitimated.

Second, world cultural models also have direct effects on mobilization through three mechanisms: the cultural construction of actorhood, increasing probability of elite schisms, and the provision of mobilizing resources and frames. In the modern era, the fundamental building block of world society is the individual (Meyer and Jepperson 2000). Individual actors are not only sanctified by the system, with a discourse of human rights, but also empowered with agency in a variety of arenas, including the political. Accordingly, participation in social movements generally has been found to correspond to a country's increasing integration into world society (Tsutsui and Wotipka 2004). For example, in 1989, it should have been little surprise that the communist states first affected were those with stronger connections to the West. Organized opposition movements such as Solidarity in Poland (Osa 2003) and individual citizens as in East Germany (Pfaff 2006) became agents of change in line with the democratic scripts of world culture. In earlier eras, different models of actorhood prevailed, and so the French Revolution was constituted around an image of citizenship and the Russian Revolution around theorization of classes as revolutionary agents.

Further, world society can create the potential for intra-elite and intra-regime schisms as it promotes the growth of new elite classes within society. Professionalization and mass education and their organizational expression in associations, universities, non-governmental organizations, and extra-institutional movements are a primary link between global and local civil society, filling gaps where state practice is decoupled from transnational scripts (Meyer 2010). These elites, when excluded from 
political institutions, are key members of successful revolutionary coalitions (Goodwin and Skocpol 1989). During the French Revolution, excluded professionals, business classes, and even aristocrats became allies of the revolutionary cause once socialized into Enlightenment ideals (Markoff 1988, 1996). Lenin's vanguard of the proletariat, both as idea and practice, emerged among the relatively elite classes of a relatively unindustrialized empire (Mann 2012), occupying a mobilizing space that fell between an exclusionary regime and pressures for reform. And elites and party members in Czechoslovakia, Hungary, and the Soviet Union saw an opportunity for reform, if not revolution, in the mounting pressure on the communist world (Lawson 2005). It is difficult to imagine such ideologically-driven schisms within regimes and elites without broader transnational cultural ideals for them to draw upon.

The discourses of the larger world environment also provide the rationales, frames, and beliefs that individual actors and movements can use to justify their actions. Revolution without ideology is hardly revolution at all, but merely coup d'etat or state failure. And revolutionary ideologies almost always have a universal component connected to transnational cultural systems (Halliday 1999). In other eras, individuals and organized oppositions framed their claims and carried out contention in the context of universal, transnational templates of politics. For example, asking what the Third Estate was during the French Revolution (Sewell 1994), and adapting transnational democratic notions into local constitutionalism in Iran, Turkey, and Russia during the first years of the twentieth century (Sohrabi 1995). As mentioned above, such ideological bases need not be democratic - the Bolsheviks adapted an alternate transnational ideology of class struggle to form their revolutionary coalition (Mann 2012). World culture may thus be Janus-faced, supporting both progressive and reactive alternatives across its system (Beck 2011).

In short, the transnational system structures collective action at the subnational level, explaining the interaction of the global and the local. The modern institutionalization of actorhood and the growth of transnational cultural models creates increasing potential for individuals and groups to act against authority, challenges the unity of exclusionary states and classes, and sanctifies the frames and ideologies of revolution. Just as the legitimacy of authority is state-exogenous, so is the legitimacy of opposition. Again, these processes are obvious in the Revolutions of 2011. Protest began with the actions of relatively young and educated urban elites shut out from meaningful participation in politics, not primarily traditional corporate groups. These "new" elites were also globally connected through the growth of civil society organizations, communication technologies, and direct personal linkages. Some activists, like the April 6th Youth Movement in Egypt, also consciously imported the model of non-violent democratic revolution from postcommunist states, adapting it and forging coalitions with local allies in new ways. Human rights, democratic participation, the rule of law, and other global discourses provided both the impetus and the necessary frames for mobilization, particularly in its earliest phrases. Contention, whether democratic or not in the long run, was affected by transnational cultural models.

Finally, the growth of world society makes the spread of contention across societies more likely, as well. Diffusion requires not only the spread of information, whether direct, indirect, or through brokerage (Tarrow 2005), but also a determination that prior events are germane to an actor's own situation (Strang and Meyer 1993). Transnational processes make both more likely. First, it is no secret the globalization has intensified 
connections among societies and, accompanied by the stunning growth of communication technologies, allows information to be spread more easily than ever before. Such practical channels for diffusion are another form of global embeddedness (Clark and Hall 2011), and contemporary embeddedness is structured in part by degrees of membership in world society (Meyer et al. 1997). Yet embeddedness matters for another reason as well. Collective action is unlikely to spread, even when it is known, without local actors who choose to adopt and adapt it to their own situation (McAdam and Rucht 1993). This is increasingly likely when similar constellations of actors exist in multiple locations, creating potential receptor sites for diffusion (Giugni 1998). As discussed above, world cultural models construct national and subnational actors in an isomorphic fashion (see Meyer 2010), which makes for an increasing likelihood of complementary innovators and adopters. These actor- and communication-centric mechanisms are evident in earlier waves of revolution where similar groups across multiple societies became revolutionary agents, for instance: Enlightened intellectuals in eighteenth century Euro-America (Markoff 1996); oppositional coalitions in 1848 Europe (Weyland 2009); and republican parties in the early twentieth century semiperiphery of Europe (Kurzman 2008; Sohrabi 2002).

Diffusion also becomes more likely when societies are structurally equivalent, displaying similar political and social structures. If actors must choose to adopt a new tactic or model of organization, then they are more likely to do so if there is a perception that its place of origin is similar and relevant (Strang and Meyer 1993). Many revolutionary waves thus appear to be regionally bounded, but this should not be confused with an effect of geographic proximity, particularly in the modern, globalized world (cf. Mann 2013). Rather, what is perceived as region is in fact a proxy for structural equivalence among societies - for example, the Middle East and North Africa is conceived to be a different geographical unit than Sub-Saharan Africa, the Mediterranean World, or the larger Asian landmass. Structural equivalence, then, often suggests the states most at risk and the possible limits of diffusion. This is seen clearly in prior revolutionary waves - the European Enlightenment Revolutions spread to a different hemisphere as the colonies of the Americas were embedded in an Atlantic social and political system (Palmer 1959), and the Color Revolutions wave broke across the multiple areas of the postcommunist world (Beissinger 2007).

More importantly, the development of world culture reifies the idea of a small and unitary world, creating the possibility for perceptions of relevance even in the absence of objective equivalence. As states and societies organize themselves along global lines they become increasingly similar in their symbolic structures even if actual practice lags. This allows for determinations of relevance between new and unexpected sitesfor example, 1989 saw after effects on non-communist regimes in South Africa and Chile (Lawson 2005) and the Color Revolutions touched places as diverse as Burma, Tibet, and Lebanon. Symbolism here often outweighs objective reality - the revolutionary slaves of 1791 Haiti were inspired by France's Declaration of the Rights of Man and of the Citizen (James 1963), and the peasant communists of China re-theorized a revolutionary ideology developed in the context of European industrialization (Mann 2012). Once diffusion has begun, new repertoires also develop that imperil existing regimes and create changes in the international conditions to which all states are subject (Markoff 1996; Tarrow 1993). Such positive feedback is dependent on the global embeddedness of national societies. Revolution in a central state often diffuses (e.g., 
1789 or 1848 in France) and revolution in semi-peripheral ones can as well (e.g., 1905 or 1917 in Russia), but revolution in truly isolated societies rarely does (e.g., 2009 in Madagascar).

In summary, world culture intensifies diffusion processes and cross-national interaction effects among states and movements. Specifically, the development of personhood constructs similar actors in multiple societies ready to transmit and receive collective action; isomorphism and symbolic universalism increase the likelihood of perceived structural equivalence and relevance; and global embeddedness affects the interrelations of societies and the possibility of positive feedback and further diffusion. It should thus be no surprise that the number of revolutionary waves has increased as world culture has grown (Beck 2011). In the Revolutions of 2011, Tunisian and Egyptian activists made direct connections with activists of the postcommunist Color Revolutions to learn and adapt their tactics, as mentioned above. Similarities in practical authoritarianism and the symbolic universalism of democratic participation made this determination of relevance seem almost inevitable in retrospect. Further, within the Middle East, a high degree of structural equivalence across societies in terms of their cultural, political, economic, and social organization made regional diffusion of an initial event quite likely. Not surprisingly, it was the societies most similar to Tunisia, such as Egypt, that saw the most effective adoption of the repertoire. Once contention had begun to spread, it became a new feature of the international dimension, threatening regimes that had seemed completely secure.

World culture created a revolutionary wave just where it might be expected to-in a region that had the most incongruence with transnationally legitimate forms and practices but was still globally embedded to some degree. To summarize in multidimensional terms, as global models develop and penetrate, they undermine state legitimacy through the contradiction of the global and the local, new political actors and actions are created, and the diffusion of contention is more likely leading to positive feedback at state and international levels. While there is a seeming tension between mechanisms that rely on either contradiction or similarity to the broader world society, this is due to world culture's influence being both practical and symbolic and interacting across multiple levels of analysis. Of the six mechanisms outlined above, three are practical and three symbolic. Practically, world cultural models delegitimate extant political structures as well as constitute social groups relatively excluded from power and similar to actors elsewhere. Symbolically, world cultural scripts authorize agency, suggest mobilizing frames, and assist with the adoption of external innovations. The dynamic between world society embeddedness and local decoupling in practice is thus a primary interaction that governs revolutions and revolutionary waves.

While some scholars of revolution and comparative-historical sociology doubt the utility of a world polity perspective (e.g., Lachmann 2010; Sohrabi 2005), this is often due to mistaking it for the teleological, value-laden expectations of modernization theory (Schofer et al. 2012), as well as a misconception that transnational social and cultural organization necessarily excludes agency. In actuality, world society research describes a contemporary system that has a constructed "modernity" as its content rather than a system that is inevitable or progressive (see Adams et al. 2005). Nor is this necessarily a structural account. In fact, agency from the legitimation of personhood is the primary mechanism by which world cultural models are adopted, adapted, and resisted (Meyer 2010; Meyer and Jepperson 2000). Theorizing revolution along these 
lines thus makes a contribution to understanding how global models are locally translated in a non-linear fashion (see Sohrabi 1995, 2002). Further, a decontextualized version of this theory can have more universal application beyond the temporal bounds of modern world society. In other times and systems, different political practices and forms might be legitimated and other actors authorized or not to act. Thus, we could imagine, for instance, developing a world cultural theory that could explain the spread of contention in a medieval Europe centered on the transnational institutions and culture of the Catholic Church, or one that considers contention within an imperial system like early modern China (see Hung 2011).

In this example of theory building, I have shown how the challenge of multidimensional thinking can be met by including all levels of analysis, stressing interaction, and accounting for relations of the constituent units. I have emphasized one under-theorized transnational condition, but this need not preclude the importance of other factors. This is, after all, the entire spirit of methodological cosmopolitanism. For example, it could be possible to build a multidimensional theory that stresses the role of the global recession of 2008 or increasing political opportunities in the shift towards a multipolar international system. These theories should certainly be built in other studies. In the next section, I show how such theories can be investigated and interactions assessed through a structured example of study design.

\section{Analyzing multidimensional revolution theory}

Multidimensional thinking requires multidimensional investigation-both interaction of multiple variables and interaction of multiple units need to be prioritized. There are different analytical tools that may meet this challenge. For example, an event history analysis with separate vectors in the regression equation for diffusion processes and effects of structural equivalence has been successfully harnessed to model diffusion more generally (see Strang and Tuma 1993). In the case of revolutionary waves, variables focused on transnational, state-centered, and subnational conditions with multilevel modeling could test the full range of factors that shape revolution. Yet to embody multidimensionality fully, the analysis would have to include multiple interaction effects, which are difficult to interpret and model (Ragin 2008). Alternatively, a comparative study design could analyze cases in detail and account for temporal dynamics across a small number of revolutions. Causal inferences here can be drawn if case selection allows for logical comparison of mechanisms (see Goertz and Mahoney 2012). Yet the constraints on how many cases can be included in a structured comparison make it difficult to analyze the entire scope of a revolutionary wave where many societies are impacted. Regression analysis may thus have trouble meeting the theorem of interaction among levels of analysis and comparative case analysis may not meet the theorem of interaction among many units of analysis.

There is another method well suited to an investigation that requires multiple interactions and multiple cases in a parsimonious fashion-qualitative comparative analysis. QCA uses Boolean logic to identify the combinations of factors that lead to a designated outcome within a set of cases (see Ragin 2008), in this instance ranging across the levels of transnational, state-centered, and subnational conditions that existed prior to the start of the revolutionary wave in 2011. In addition to emphasizing 
interaction, QCA also works well for samples larger than a few cases but smaller than scores of observations, here 16 Middle Eastern and North African countries that experienced varying levels of contention. Of course, like any study of a single time point, this does not vary the transnational environment as a whole, and therefore its findings are contextual. Ahistorical generalizability would be most possible through the study of multiple revolutionary waves, which suggests the use of multiple, or even global, event history analyses or macro-comparisons of waves. Neither could be accomplished in anything less than a full book-length study.

I thus focus on a fuzzy set QCA analysis that incorporates the interactions between different levels of analysis and the outcome of contention in the Revolutions of 2011. Additionally, I consider the dynamics of revolution for each of the levels of analysis, matching an exemplar of study design to the exemplar of theory building.

Fuzzy set qualitative comparative analysis

QCA begins by identifying the factors that may have some bearing on an outcome and coding them across the cases at hand. Traditionally, scholars have tended to define revolution as successful transformation of at least political, if not also social, structures accompanied by mass uprisings from below (e.g., Skocpol 1979; Goldstone 1991). A more appropriate conception for 2011 might be Tilly's (1993) revolutionary situations. Revolutionary situations occur when "two or more blocs make effective, incompatible claims to control the state, or to be the state" (Tilly 1993, p. 10). I extend this concept to nonviolent mobilizations by considering episodes of sustained contention that threaten a regime's persistence, and for shorthand purposes I will refer to this as a revolutionary situation. By this definition, Egypt, Tunisia, and Libya have certainly experienced a revolutionary situation as well as a change in regime sufficient to be named political revolutions, though whether or not their revolutions will constitute social revolutions remains to be seen. Further, the repressed but intense contention in Bahrain and Syria and Yemen's sustained episodes of dual claims can be denoted revolutionary situations. On the other hand, Algeria, Jordan, Iraq, Morocco, Oman, Lebanon, Kuwait, and Saudi Arabia each experienced protests but without challenges sharp or sustained enough to meet the criteria of dual claims. Finally, Qatar and the United Arab Emirates have had little protest at all. The outcomes are summarized in the Appendix.

Rather than basing the coding of independent variables solely on summary judgments of absence or presence, I operationalize five factors prominent in the study of revolution, selected to represent conditions prior to mobilization across different levels of analysis (see the Appendix for details of measurement and fuzzy set construction). First, I account for transnational factors with two indicators: a common measure of a country's embeddedness in wider world society drawn from data on international nongovernmental organization memberships (which operationalizes the world cultural argument made above), and economic pressure measured by the GDP growth rate since the global recession beginning in 2008. Economic strain is a commonly theorized cause of revolution (Foran 2005; Skocpol 1979; Paige 1975; Wallerstein 1980) that connects the fiscal fortunes of states to international economic structures. Thus, while both factors are measured nationally, they are transnationally dependent and best seen as state-exogenous variables that help account for the international context. Next, I include state-centered factors by operationalizing a consistent finding in the study of revolution-regimes with 
exclusionary political institutions are more likely to experience revolution (e.g., Foran 2005; Goldstone 2011; Goodwin 2001; Goodwin and Skocpol 1989). Here this is measured with a regime's score on the common Polity measure of democracy. In the context of a contemporary global civil society that sanctifies democratic institutions, human rights, and individual actorhood, the existence of political exclusion is also an indicator of contradiction between the global and the local. Finally, two indicators account for subnational conditions for mobilization: demographic pressure exerted by youth bulges, and a history of opposition to the state. While prior work has conceptualized demographic pressure as a state-centered factor (Goldstone 1991), it is better viewed as a condition that affects the likelihood of mobilization as large cohorts of youth have trouble finding employment in stagnant economies, face political frustration in authoritarian settings, and provide fertile ground for the recruitment of participants in contention (Urdal 2006). Mobilization is also more likely when collective actors have both the symbolic memories of resistance to draw upon (Foran 2005; Reed and Foran 2002) and the mobilizing resources and organizational structures that prior contentious episodes provide (Chang 2008; Osa 2003; Wickham-Crowley 1992). These five prior conditions thus account for much of the needed terrain - multiple levels of analysis that interact and generate variation in the outcomes of a revolutionary wave.

Fuzzy set QCA examines the combinations of factors to provide conjunctural solutions, whose reliability can be gauged by how consistently a combination of causes yields the outcome in question. The initial results are further minimized to more parsimonious combinations using the logic of counterfactuals (see Ragin 2008). As the five factors considered here are widely theorized to yield revolution only when present, this "intermediate solution" is more telling than the complex solution. The empirically consistent results are presented in Fig. 2. Alternative results and analytical details are presented in the Appendix and Table 2.

The results of analysis support a multidimensional view of the Revolutions of 2011 by accounting for four of the six revolutionary situations that occurred with a role for

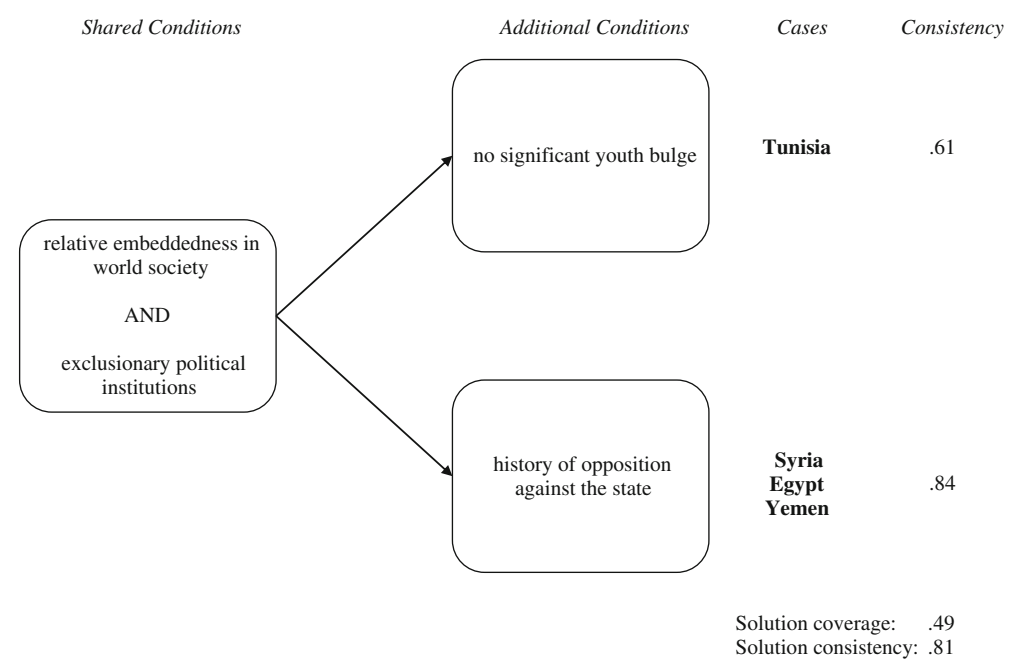

Fig. 2 Intermediate results of fuzzy set qualitative comparative analysis of revolution in sixteen Middle Eastern countries in 2011 
each level of analysis. In each of these cases, relative embeddedness in world society, hence susceptibility to the diffusion of transnational cultural scripts, and political exclusion, hence contradiction with world society and a state-centered cause, are necessary conditions for sustained contention. In one case-Tunisia - these conditions combine with a youth bulge that is relatively less significant, and in the other threeEgypt, Syria, and Yemen - they combine with a history of opposition against the state to yield revolutionary situations. The latter result suggests that successful adoption of the diffusing Tunisian model of revolution was more likely when activists had prior mobilizing resources to draw upon. The overall consistency of the results is acceptable at 0.81 , but the lack of a highly consistent solution for Tunisia perhaps points to the role of contingency in revolution - no theory could have predicted that the self-immolation of a fruit seller would set off the protests and elite schisms that would eventually overthrow a dictator. Notably, each of the four cases explained was relatively more globally embedded in 2011. In particular, Egypt was almost four times more connected through INGO memberships than the regional average and Tunisia ranked third among Middle Eastern and North African countries on this indicator (see Table 1 in the Appendix).

This shows support for exactly what a world cultural account of revolution expects - regimes are more susceptible when a country is linked to world society, when political forms and practices are normatively incongruent, and when subnational uprising is encouraged by the content of world culture. This is seen in the interaction between world linkage, political exclusion, and histories of opposition. Even so, there are clear outliers - the solutions found do not cover the revolutionary situations in Libya and Bahrain, societies that were relatively unconnected to world society, and the solutions do not appear to account for the lack of sustained contention in the relatively globally embedded societies of Algeria, Jordan, and Morocco, the latter two of which also have politically exclusive regimes. This points to the need for considering interactive mechanisms rather than single variable models of revolution. Nor do the solutions, by themselves, tell us much about the diffusion of protest. Thus, in the next section I consider the evidence for each level of analysis and examine outliers and counterfactuals in more detail.

\section{Transnational conditions}

In addition to the world cultural conditions affecting Middle Eastern and North African societies in 2011, two other transnational factors could be relevant. The global economic downturn that began in 2008 affected growth rates substantially and may have provided a further strain on neo-patrimonial regimes dependent on the provision of services and economic opportunities to maintain their rule. The sharp decline in energy prices in 2008 meant that the OPEC states were most affected by this strain. The secondary analyses (see Table 2 in the Appendix), while inconsistent, do suggest that economic strain may have played a role in Libya. Yet most regimes with oil wealth saw little contention, represented in the primary results that exclude economic strain as a key factor.

Second, the relative decline of American hegemony and a shift towards more multipolarity in the international system could also have had regional affects (see Foran 2005). Perhaps foreign patrons were less likely to be actively involved than before in 
helping maintain client regimes. For example, the Obama administration grudgingly accepted that the time had come for Mubarak to resign and encouraged the neutrality of the Egyptian armed forces, and also brokered a negotiated settlement in Yemen. Yet in contrast to an isolationist model of hegemonic decline, foreign military power continued to matter-multilateral intervention in Libya, Saudi support for Bahrain's monarchy, and competing material assistance in Syria each shaped those revolutionary situations' trajectory. In fact, intervention, whether militarily or not, may have been a key factor in determining the difference between accomplished revolution and failed or continued revolutionary situation (Goldstone 2013). While the decline of American hegemony may have provided an additional political opportunity once contention was underway, it does not seem that the onset of revolutionary situations depended upon it.

In summary, it appears that at least one of the outliers, revolutionary onset in Libya, might be explained at this level of analysis by economic strain, and that the role of foreign power had shaping effects on the course of the conflicts.

\section{State-centered conditions}

While each of the regimes that fell during 2011 was autocratic, not all autocracies experienced sustained contention. The difference lies in a distinction not accounted for by a general measure of political exclusion: every monarchy except for Bahrain was able to weather successfully the diffusion of protest. There is an irony for revolution theory here-monarchy was in earlier eras a politically weak structure when faced with mass uprising, yet the monarchies that have persisted into the modern world may be paradoxically stronger than their global incongruence and local political practices would suggest. This may occur because monarchies have other sources of legitimation (Goldstone 2011) - in Weberian terms, traditional and religious authority - that allow them to sustain contradictory political and social structures successfully. Practically, Middle Eastern monarchies are also based on tribes and clans that could provide a more robust source of mass support than those constituencies available to secular autocrats. Interestingly, the one monarchy that did face sustained challenge-Bahrain - is a Sunni dynasty ruling over a predominantly Shiite population, suggesting limited popular legitimacy. But an emphasis on monarchy as a durable power arrangement may obscure an equally important factorhow regimes responded to contention. The Gulf monarchies all have oil wealth, again except for Bahrain, that allowed for both pre-emptive and responsive economic concessions (Goldstone 2013).

Conciliation also seems to be a key determinant in the region more broadly. Every regime that relied primarily on repression of protest ended up fueling more contention-Tunisia, Egypt, Libya, Bahrain, and Syria. In contrast, those that enacted or promised significant political concessions remained in place: Jordan and Morocco promised resumptions of moves towards constitutional monarchy, and Oman, Kuwait, and Saudi Arabia each announced electoral or parliamentary reforms. This mirrors a common finding in research on mobilization-repression backfires just as often as it succeeds (Chang 2008; Kurzman 
1996; Pfaff 2006; Rasler 1996). The more liberal regimes did not have to go so far with concession or repression (see Table 1): Algeria merely lifted the 19 year old state of emergency; in Iraq, Maliki merely promised not to seek office for a third term, and protest in Lebanon yielded no notable response. This suggests that significant reactions to protest were only necessary for the most globally incongruent regimes, confirming the interaction of world linkage and political exclusion as necessary prior conditions for contention.

In short, material wealth, specific regime type, and the dynamics of repression and concession seem to explain some of the variation in outcomes, covering the outlier of Bahrain and the counterfactuals of Algeria, Jordan, and Morocco.

\section{Subnational conditions for mobilization}

The primary fuzzy set analysis shows little role for demographic pressure in explaining the occurrence of revolution in 2011, but this should not be overstated. First, the less consistent results in the secondary analysis suggest its impact in Libya, Syria, Egypt, and Yemen. Second, prior work on youth bulges has found a monotonic effect (Urdal 2006), which may be difficult to capture through fuzzy sets. Even so, some countries with large youth bulges, like Iraq and Oman, did not experience revolutionary situations and one with a small youth bulge, Bahrain, did (see Table 1).

A more consistent effect seems to be had in the role of a history of opposition against the state. As found in the primary analysis, some activists were able to draw upon the resources and structures left over from prior episodes of mobilization. In Egypt, early adopters like April 6th Youth Movement drew on the networks and lessons of prior protest like the Kefaya Movement (see Clarke 2011) and the large network of the Muslim Brotherhood was finally activated to rally support and to sustain demonstrations in Tahrir Square (cf. Kandil 2011), forming a successful revolutionary coalition (Austin Holmes 2012). In Yemen, peaceful protest in the capital Sana'a was accompanied by continued resistance from regional tribes and clans (Goldstone 2011), and the Syrian opposition drew on existing social networks that had created a safe space for ideation and recruitment (Leenders 2012).

Histories of opposition are also important for memory as much as practicality (Reed and Foran 2002; Selbin 2010). In Syria, defection of individual soldiers and whole military units came quickly in response to orders to repress demonstrations or face execution. Quite simply, the non-Alawite recruits did not appear to be ready to repeat the 1982 massacre of Hama for a regime they did not support. Memory may also help account for the revolutionary situations in Libya and Bahrain, even though neither society had faced armed rebellions in decades. In Bahrain, the first post-independence parliament had been dissolved in 1974 and harsh repression of dissent continued through 1999, suggesting the possibility of a culture of resistance. In Libya, the protestors of 2011 raised the former flag of the Kingdom of Libya that had been overthrown by Qaddafi in 1969.

Yet accounting for this ambiguity in what constitutes a history of opposition against the state does not change the results of the analysis (see the Appendix), perhaps for two reasons. First, secondary analyses suggest that a history of opposition was a key factor in the several cases that had protest only. Thus, it has insufficient explanatory power by itself for revolutionary outcomes (see Table 3 in the Appendix). Second, memory can 
cut both ways. The three Middle Eastern and North African societies with the most violent histories of conflict saw little protest even though the Algerian civil war, Lebanese sectarian conflicts, and the Iraqi insurgency could have provided both practical and symbolic oppositional resources. While such conflicted histories may make potential participants wary of future instability, it is also worth noting that each of these regimes was relatively politically liberal, scoring as partial democracies on the Polity scale. In short, favorable subnational conditions for mobilization seem to have had effects only through interaction with other factors as found in the fuzzy set analysis.

\section{Diffusion}

I have noted previously that the diffusion of protest in 2011 took place in two stages. First, once protest had begun in Tunisia, activists translated, both literally and figuratively, the tactics of nonviolent movements in the Color Revolutions. Second, once Tunisian contention successfully helped overturn the Ben Ali regime, diffusive mechanisms carried the model to other countries. In the first process, the relative embeddedness of Tunisia in the international community mattered-models are only adapted when they are both known and deemed to be relevant. This is borne out by the significant role for world linkage in the results of fuzzy set QCA, and Tunisia's relatively high score on this measure. In the second process, success and structural equivalence played a role-adoption is more likely when a tactic proves itself in a similar social situation. Notably, protest did not spread for the first month of the Tunisian demonstrations, and it was not until the regime fell on January 14th that activists elsewhere seized upon the example. This again implicates the role of contingency in explaining revolutionary waves - had the Tunisian uprising failed due to exhaustion or repression, it is more difficult to imagine the spread of the model.

But success alone was not enough to determine adoption; diffusion also clearly occurred across structurally equivalent societies. Thus, the wave was mostly regionally bounded, affecting only nations similar in social structure, culture, and language. Further, those societies that most closely resembled Tunisia-secular authoritarian states - saw the most successful adoption of the tactic as noted above in the fuzzy set results discussion. And the most globally embedded of these, such as Egypt, also drew upon international models directly suggesting how positive feedback loops between transnational conditions and mobilization can form.

Diffusion processes also shaped outcomes to some degree. There is often an advantage for initiating movements over later spin-offs (McAdam 1995). Initiators have the element of novelty and surprise, and elites are thus less able to respond effectively. As a tactic spreads, however, elite learning and adaption also occurs and the chances for success diminish (Beissinger 2007). After initial Tunisian success, Egypt and Yemen had significant protests beginning in January 2011. In mid-February, protests began in Libya and Bahrain, and it was not until mid-March that significant demonstrations occurred in Syria. The timing of these revolutionary situations correlates well with their outcomes - success in the earliest episodes (Tunisia, Egypt, and Yemen), more contentious episodes in the middle that sparked international intervention for or against (Libya and Bahrain), and devolution into drawn out civil war in the later episode (Syria). A diffusive theory of revolutionary waves thus can include the crucial effects of time and stages in revolutionary episodes (see Goldstone 1991; 
Sohrabi 1995). Even so, it is a subsidiary factor shaping trajectories as sustained contention is predicated on favorable prior conditions. This is seen in the lack of correlation between the timing of diffusion in the negative cases-Algeria, Jordan, Lebanon, and Oman also saw early protests but these did not amount to revolution.

\section{Summary}

In short, a multidimensional view that stresses interaction among levels of analysis and units of analysis is supported by the case of the Revolutions of 2011. The results of fuzzy set QCA analysis suggest a primary role for the interaction of world linkage, regime type, and histories of opposition as key factors in explaining where revolutionary situations occurred, which is anticipated by the theoretical model. Examination of the nuances of these conditions and additional factors helps resolve the seeming outliers and counterfactuals. Specifically, it seems that in Libya the combination of economic strain, a historical memory of society before dictatorship, and the regime's reliance on repression of protest alone may have contributed to revolutionary onset. International intervention then secured the rebellion's base in Benghazi and led to its success. In Bahrain, the monarchy perhaps lacked the legitimacy and resources of other Gulf states to make meaningful concessions, and the regime was forced to rely on repression and Saudi support to maintain its power. In Algeria, even though society was globally embedded, a relatively more liberal regime type and early concession helped forestall protest turning into revolution. And in Jordan and Morocco, it seems the monarchical regimes were able to rely on traditional sources of legitimation and concession to weather the storm. Secondary analyses also suggest that the countries experiencing only protest lacked the key interaction of global embeddedness and political exclusion found in the fuzzy set results of revolutionary situations (see Table 3 ). Revolutionary theory that emphasizes multidimensional interaction thus can be substantiated analytically.

\section{Conclusions}

I have argued that an explanation of revolutionary waves like that in 2011 requires moving beyond case-centered theories of revolution to a conscious and explicit inclusion of transnational factors. In essence, a social science of revolution is needed in which multidimensionality and interaction are the core theoretical images. I further argue that it is time to place revolutionary waves at the center of revolutionary theory. Thus, theorization should address four principles for including transnational dynamics: 1) identification of international conditions that matter, how they are linked to both 2) state-centered causes and 3) mobilizing processes, and 4) their relationship with the spread of contention. I then have provided structured examples of theory building and study design, showing that transnational factors had a role to play in the Revolutions of 2011 when combined with state-centered strains and favorable subnational conditions for mobilization. In short, it should be no surprise that Arab countries saw springtime, even if we could not have predicted 2011 as the exact year of its arrival. As Fig. 3 
meta-axiom: multiple levels of

analysis, multiple units, and 4

through interaction

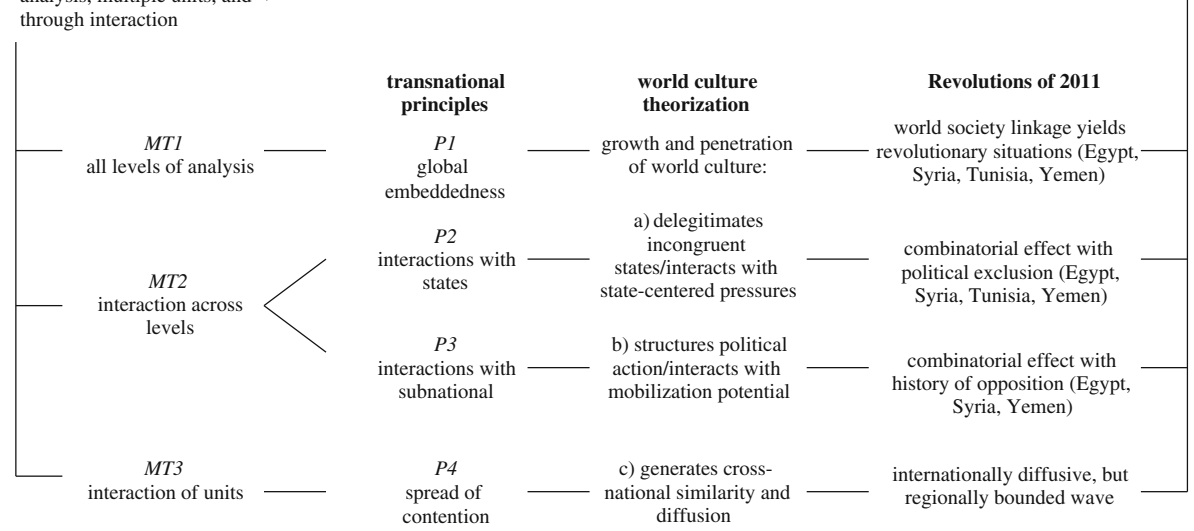

Fig. 3 From meta-axiom to the revolutions of 2011 and back again

outlines, the empirical examination verifies the importance of principles of transnational theorization, which in turn suggests the utility of the metatheoretical framework for understanding revolution.

I have emphasized here one under-theorized transnational factor in the social science of revolution, world cultural dynamics, but this does not preclude the importance of other causal conditions and mechanisms. Revolutionary waves are complex events and a theory that only operates at one level of explanation is likely to fail. Nor is qualitative comparative analysis the only method for exploring this complexity; the social science of revolution should welcome new and alternative methods whether their provenance is from the comparativehistorical tradition or not. Finally, the theory does not rule out, and the analysis confirms, that contingency has a large role to play in shaping revolution. Yet this does not mean that explanation is futile, rather it means that explanation must be holistic.

The persistent central problem in understanding revolution is to explain the coincidence of conditions favorable to revolution. Yet each generation of revolutionary theory has developed in a wavering fashion, returning to a level of analysis rejected by its predecessor. Accordingly, the global and transnational level never became a consistent point of discussion. The continued "surprising" occurrence of revolutionary waves, whether 1848, 1989, or 2011, calls upon us to think otherwise. And this requires cosmopolitan theories that can meet the challenge of the framework I have outlined. There is thus no need for us to throw out the bathwater of prior perspectives, whether from the first, second, third, or fourth generations, and risk losing the baby of explanation. After all, waves require water.

Acknowledgments The author thanks John W. Meyer, Charles Kurzman, Robin M. Cooper, Pierre Englebert, three reviewers for Theory and Society, and the participants of the Irvine Comparative Sociology Workshop for their helpful comments on prior versions of this article. Previous variants were presented at the American Sociological Association in 2012, Social Science History Association in 2012, California Sociological Association in 2012, Department of Sociology at the University of Arizona in 2013, and the Capitalism, the Politics of Inequality, and Historical Change Mini-Conference in 2013. 


\section{Appendix}

Table 1 presents the raw data used for five fuzzy set codes in QCA analysis. Each measure was calibrated into fuzzy sets using scores for a crossover point between membership and non-membership, and upper and lower thresholds indicating full membership or non-membership respectively.

Table 1 Indicators for five causes of revolution for 16 Middle Eastern countries in 2011

\begin{tabular}{|c|c|c|c|c|c|c|}
\hline \multirow[t]{2}{*}{ Country } & $\begin{array}{l}\text { Economic } \\
\text { pressure }\end{array}$ & $\begin{array}{l}\text { Demographic } \\
\text { pressure }\end{array}$ & $\begin{array}{l}\text { Political } \\
\text { exclusion }\end{array}$ & $\begin{array}{l}\text { History of } \\
\text { opposition }\end{array}$ & $\begin{array}{l}\text { World } \\
\text { linkage }\end{array}$ & Outcome \\
\hline & $\begin{array}{l}\text { GDP \% } \\
\text { growth, } \\
2008-2010\end{array}$ & $\begin{array}{l}\% \text { of } 15+\text { pop. } \\
\text { ages } 15-24, \\
2010\end{array}$ & $\begin{array}{l}\text { Regime } \\
\text { democracy } \\
\text { score, } 2010\end{array}$ & $\begin{array}{l}\text { Contention } \\
\text { since } 1980\end{array}$ & $\begin{array}{l}\text { \# of INGOs } \\
\text { per GDP } \\
\text { per capita, } \\
2010\end{array}$ & $\begin{array}{l}\text { Type of } \\
\text { contention }\end{array}$ \\
\hline Egypt & $5.66 \%$ & $28.8 \%$ & -3 & Yes & 0.486 & $\begin{array}{l}\text { Political } \\
\quad \text { revolution }\end{array}$ \\
\hline Libya $^{a}$ & $2.95 \%$ & $27.3 \%$ & -7 & No & 0.037 & $\begin{array}{l}\text { Political } \\
\text { revolution }\end{array}$ \\
\hline Tunisia & $3.56 \%$ & $24.6 \%$ & -4 & No & 0.210 & $\begin{array}{l}\text { Political } \\
\text { revolution }\end{array}$ \\
\hline Bahrain & $4.63 \%$ & $18.2 \%$ & -8 & No & 0.021 & $\begin{array}{c}\text { Revolutionary } \\
\text { situation }\end{array}$ \\
\hline Syria & $4.57 \%$ & $32.2 \%$ & -7 & Yes & 0.168 & $\begin{array}{c}\text { Revolutionary } \\
\text { situation }\end{array}$ \\
\hline Yemen & $5.07 \%$ & $39.8 \%$ & -2 & Yes & 0.195 & $\begin{array}{c}\text { Revolutionary } \\
\text { situation }\end{array}$ \\
\hline Algeria & $2.80 \%$ & $28.4 \%$ & 2 & Yes & 0.173 & Protest \\
\hline Jordan & $5.01 \%$ & $30.5 \%$ & -3 & No & 0.149 & Protest \\
\hline Iraq & $6.09 \%$ & $33.8 \%$ & 3 & Yes & 0.089 & Protest \\
\hline Kuwait & $1.08 \%$ & $21.6 \%$ & -7 & No & 0.011 & Protest \\
\hline Lebanon & $8.26 \%$ & $26.2 \%$ & 7 & Yes & 0.092 & Protest \\
\hline Morocco & $4.67 \%$ & $27.5 \%$ & -6 & No & 0.345 & Protest \\
\hline Oman & $5.97 \%$ & $30.8 \%$ & -8 & No & 0.016 & Protest \\
\hline Saudi Arabia & $2.98 \%$ & $24.9 \%$ & -10 & Yes & 0.050 & Protest \\
\hline Qatar & $15.43 \%$ & $16.7 \%$ & -10 & No & 0.005 & None \\
\hline $\begin{array}{c}\text { United Arab } \\
\text { Emirates }\end{array}$ & $1.04 \%$ & $26.6 \%$ & -8 & No & 0.021 & None \\
\hline $\begin{array}{l}\text { Fuzzy set } \\
\text { crossover }\end{array}$ & $3.00 \%$ & $25.0 \%$ & 0 & - & 0.129 & - \\
\hline $\begin{array}{c}\text { Membership } \\
\text { threshold }\end{array}$ & $2.00 \%$ & $30.0 \%$ & -6 & - & 0.197 & - \\
\hline $\begin{array}{l}\text { Non-membership } \\
\text { threshold }\end{array}$ & $4.00 \%$ & $20.0 \%$ & 6 & - & 0.062 & - \\
\hline
\end{tabular}

${ }^{\text {a }}$ GDP percent change calculated from 2008 to 2009 and 2010 INGOs calculated per 2009 GDP per capita due to missing data 
First, economic pressures are measured using the average annual growth in real gross domestic product between 2008 and 2010 (World Bank 2013). For fuzzy set coding, the crossover point of 3 (sluggish growth for the developing world) is used. Full membership in economic pressure set at $2 \%$ and full non-membership set at $4 \%$. These thresholds err on the side of overstating economic strain.

Next, demographic pressure is measured using the percent of the population in 2010 between ages 15 and 24 as a percent of the population older than 15 taken from the United Nations Population Division (2010) statistics. While the effect of youth bulges on political instability generally is monotonic, cohorts of young adults at about a third of the adult population raises the chance for instability by $150 \%$ as compared to cohorts that average $15 \%$ (Urdal 2006). Accordingly, for fuzzy set calibration the crossover is $25 \%$, and 20 and $30 \%$ are the lower and upper thresholds.

Third, the presence of exclusionary political institutions is measured using a standard indicator: the Polity score for regime democracy in 2010 (Marshall and Jaggers 2011). The scale ranges from -10 to 10 where higher values indicate greater levels of democratic practice, and the range of -6 to 6 represents anocracies. The crossover point is set to 0 and the bounds of political exclusion or not are set to the outside of the anocratic range.

History of opposition is coded dichotomously on whether or not there has been organized armed anti-state contention since 1980 (roughly the generation preceding 2011). For fuzzy set coding, all countries are thus set to full membership or nonmembership. Seven cases display a culture of opposition: Egypt for its Islamist rebellions; Syria for the activities of the Muslim Brotherhood in the early 1980s; Yemen with its civil war and myriad tribal conflicts; Algeria from its experience of Islamist rebellion and civil war; Iraq for the recent insurgency and a history of Shiite and Kurdish uprisings; Lebanon from its lengthy civil war and conflicts; and, finally, Saudi Arabia due to the Islamist terror campaigns of the 1990s and 2000s. Alternate fuzzy set codings that account for the intensity of these experiences and memories of previous eras of resistance yield similar results in analysis.

Fifth, I use a standard measure of global embeddedness and linkage to broader world society: the number of international non-governmental organization memberships in 2010 (cumulative count of organization types A-D in the Union of International Associations' 2011 yearbook). As organizational memberships are unequally distributed, I standardize them by GDP per capita, which accounts for skew in membership due to a society's level of relative development and size. Unfortunately, alternate measures of inequality (see Beckfield 2010; Hughes et al. 2009) are not available through 2010. Fuzzy set membership is calibrated around embeddedness or not, relative to the region. The crossover point is set at the region average of 0.129 with membership and nonmembership thresholds at 0.5 standard deviation above or below the mean.

Finally, outcomes of contention include political revolutions (change in regime), revolutionary situations (sustained contention and competing claims to power), protests of other levels of intensity, and no contention.

The primary analyses (see Fig. 1) consider only solutions that are consistent at a 0.70 level for revolutionary situations or revolution (per Ragin 2008). Table 2 presents the results of secondary analyses where inconsistent solutions are considered. The results, while relatively inconsistent, show support for conjunctural causation across multiple levels of analysis, particularly linkages to transnational conditions, mirroring the results 
of the primary analysis. Table 3 presents the results of analysis for the outcome of protest only (as compared to revolutionary situations or no contention) consistent at the 0.70 level. The solutions suggest the importance of a history of opposition in several cases, but each is missing the key combination of linkage to world society and political exclusion.

Table 2 Consistent and inconsistent solutions from fuzzy set qualitative comparative analysis of revolution in 16 Middle Eastern countries in 2011

\begin{tabular}{llll}
\hline Solution & Coverage & Consistency & Cases \\
\hline $\begin{array}{l}\text { Economic strain * political exclusion * } \\
\quad \text { youth bulge * } \text { opposition } \\
\begin{array}{l}\text { World linkage * economic strain * political } \\
\text { exclusion * youth bulge * } \sim \text { opposition }\end{array}\end{array}$ & 0.29 & 0.58 & Qatar, Bahrain, Tunisia \\
$\begin{array}{l}\text { World linkage * } \begin{array}{l}\text { economic strain * political } \\
\text { exclusion * youth bulge * opposition }\end{array} \\
\begin{array}{l}\text { Solution total } \\
\hline\end{array}\end{array}$ & 0.40 & 0.40 & UAE, Libya \\
\hline
\end{tabular}

$\sim$ indicates absence of a condition

Table 3 Consistent solutions from fuzzy set qualitative comparative analysis of protest only in 16 Middle Eastern countries in 2011

\begin{tabular}{llll}
\hline Solution & Coverage & Consistency & Cases \\
\hline $\begin{array}{l}\sim \text { Economic strain * political exclusion * youth } \\
\text { bulge * } \sim \text { opposition }\end{array}$ & 0.33 & 0.74 & Jordan, Morocco \\
$\begin{array}{c}\sim \text { World linkage * } \sim \text { economic strain * } \sim \text { political } \\
\text { exclusion * youth bulge * opposition }\end{array}$ & 0.20 & 0.95 & Iraq, Lebanon \\
$\begin{array}{l}\sim \text { World linkage * economic strain * political } \\
\quad \text { exclusion * } \sim \text { youth bulge * opposition }\end{array}$ & 0.08 & 0.98 & Saudi Arabia \\
$\begin{array}{l}\text { World linkage * economic strain * } \sim \text { political } \\
\text { exclusion * youth bulge * opposition }\end{array}$ & 0.08 & 0.99 & Algeria \\
Solution total & 0.66 & 0.84 & \\
\hline
\end{tabular}

$\sim$ indicates absence of a condition

\section{References}

Adams, J., Clemens, E. S., \& Orloff, A. S. (2005). Remaking modernity: Politics, history, and sociology. Durham: Duke University Press.

Arrighi, G., Hopkins, T. K., \& Wallerstein, I. M. (1989). Antisystemic movements. London: Verso.

Austin Holmes, A. (2012). There are weeks when decades happen: structure and strategy in the Egyptian revolution. Mobilization, 17, 391-410.

Beck, U. (2002). The cosmopolitan society and its enemies. Theory, Culture and Society, 19, 17-44.

Beck, C. J. (2011). The world-cultural origins of revolutionary waves: five centuries of European contention. Social Science History, 35, 167-207.

Beck, U., \& Sznaider, N. (2006). Unpacking cosmopolitanism for the social sciences: a research agenda. The British Journal of Sociology, 57, 1-23. 
Beckfield, J. (2010). The social structure of the world polity. American Journal of Sociology, 115, 1018-1068.

Beissinger, M. R. (2007). Structure and example in modular political phenomena: the diffusion of bulldozer/ rose/orange/tulip revolutions. Perspectives on Politics, 5, 259-276.

Boswell, T. (2004). Hegemonic decline and revolution: When the world is up for grabs. In T. Reifer (Ed.), Globalization, hegemony, \& power: Antisystemic movements and the global system (pp. 149-161). Boulder: Paradigm Publishers.

Brinton, C. ([1938] 1965). The anatomy of revolution. New York: Vintage.

Chang, P. Y. (2008). Unintended consequences of repression: alliance formation in South Korea's democracy movement (1970-1979). Social Forces, 87, 651-677.

Chartier, R. (1991). The cultural origins of the french revolution. Durham: Duke University Press.

Clark, R., \& Hall, J. (2011). Migration, international telecommunications, and human rights. Sociological Forum, 26, 870-896.

Clarke, K. (2011). Saying 'enough': authoritarianism and Egypt's Kefaya movement. Mobilization, 16, 397416.

Davies, J. C. (1962). Toward a theory of revolution. American Sociological Review, 27, 5-19.

Emirbayer, M., \& Goodwin, J. (1996). Symbols, positions, objects: toward a new theory of revolutions and collective action. History and Theory, 35, 358-374.

Farhi, F. (1990). States and urban-based revolutions: Iran and Nicaragua. Urbana: University of Illinois Press.

Foran, J. (1993). Theories of revolution revisited: toward a fourth generation? Sociological Theory, 11, 1-20.

Foran, J. (2005). Taking power: On the origins of third world revolutions. New York: Cambridge University Press.

Foran, J., \& Goodwin, J. (1993). Revolutionary outcomes in Iran and Nicaragua: coalition fragmentation, war, and the limits of social transformation. Theory and Society, 22, 209-247.

Gause, F. G., III. (2011). Why Middle East studies missed the Arab spring. Foreign Affairs, 90, 81-90.

Giugni, M. (1998). The other side of the coin: explaining crossnational similarities between social movements. Mobilization, 3, 89-105.

Goertz, G., \& Mahoney, J. (2012). A tale of two cultures: Qualitative and quantitative research in the social sciences. Princeton: Princeton University Press.

Goldfrank, W. L. (1979). Theories of revolution and revolution without theory. Theory and Society, 7, 135165.

Goldstone, J. A. (1991). Revolution and rebellion in the early modern world. Berkeley: University of California Press.

Goldstone, J. A. (2001). Toward a fourth generation of revolutionary theory. Annual Review of Political Science, 4, 139-187.

Goldstone, J. A. (2003). Comparative historical analysis and knowledge accumulation in the study of revolutions. In J. Mahoney \& D. Rueschemeyer (Eds.), Comparative historical analysis in the social sciences (pp. 41-90). New York: Cambridge University Press.

Goldstone, J. A. (2011). Understanding the revolutions of 2011. Foreign Affairs, 90, 8-16.

Goldstone, J. A. (2013). Bringing regimes back in - explaining success and failure in the Middle East revolts of 2011. Retrieved from http://papers.ssrn.com/abstract=2283655.

Goodwin, J. (2001). No other way out: States and revolutionary movements, 1945-1991. New York: Cambridge University Press.

Goodwin, J., \& Skocpol, T. (1989). Explaining revolutions in the contemporary third world. Politics \& Society, $17,489-510$.

Gould, R. (1995). Insurgent identities: Class, community, and protest in Paris from 1848 to the commune. Chicago: University of Chicago Press.

Halliday, F. (1999). Revolution and world politics: The rise and fall of the sixth great power. Durham: Duke University Press.

Hughes, M. M., Peterson, L., Harrison, J. A., \& Paxton, P. (2009). Power and relation in the world polity: the INGO network country score, 1978-1998. Social Forces, 87, 1711-1742.

Hung, H. (2011). Protest with Chinese characteristics: Demonstrations, riots, and petitions in the Mid-Qing dynasty. New York: Columbia University Press.

Huntington, S. P. (1968). Political order in developing societies. New Haven: Yale University Press.

James, C. L. R. (1963). The Black Jacobins: Toussaint L'Ouverture and the San Domingo revolution. New York: Random House.

Johnson, C. (1966). Revolutionary change. New York: Little, Brown and Company.

Kandil, H. (2011). Islamizing Egypt? Testing the limits of gramscian counterhegemonic strategies. Theory and Society, 40, 37-62. 
Katz, M. (1997). Revolutions and revolutionary waves. New York: St. Martin's.

Keddie, N. R. (Ed.). (1995). Debating revolutions. New York: New York University Press.

Kimmel, M. S. (1990). Revolution: A sociological interpretation. Philadelphia: Temple University Press.

Kuran, T. (1995). The inevitability of future revolutionary surprises. American Journal of Sociology, 100, $1528-1551$.

Kurzman, C. (1996). Structural opportunity and perceived opportunity in social-movement theory: the Iranian revolution of 1979. American Sociological Review, 61, 153-170.

Kurzman, C. (2004). Can understanding undermine explanation? The confused experience of revolution. Philosophy of the Social Sciences, 34, 328-351.

Kurzman, C. (2008). Democracy denied, 1905-1915: Intellectuals and the fate of democracy. Cambridge: Harvard University Press.

Lachmann, R. (2010). States and power. Cambridge: Polity Press.

Lawson, G. (2005). Negotiated revolutions: The Czech Republic, South Africa and Chile. Aldershot: Ashgate Publishing.

Leenders, R. (2012). Collective action and mobilization in Dar'a: an anatomy of the onset of Syria's popular uprising. Mobilization, 17, 419-434.

Mann, M. (2012). Sources of social power, volume 3: Global empires and revolution, 1890-1945. Cambridge: Cambridge University Press.

Mann, M. (2013). Sources of social power, volume 4: Globalizations, 1945-2011. Cambridge: Cambridge University Press.

Markoff, J. (1988). Allies and opponents: nobility and third estate in the spring of 1789. American Sociological Review, 53, 477-496.

Markoff, J. (1996). Waves of democracy: Social movements and political change. Thousand Oaks: Pine Forge Press.

Marshall, M. G., \& Jaggers, K. (2011). Polity IV project: Dataset users' manual. Severn: Center for Systemic Peace.

Mazzetti, M. (2011). Obama faults spy agencies' performance in gauging mideast unrest, officials say. The New York Times, February 5, p. a6.

McAdam, D. (1995). 'Initiator' and 'spin-off' movements: Diffusion processes in protest cycles. In M. Traugott (Ed.), Repertoires and cycles of collective action (pp. 217-239). Durham: Duke University Press.

McAdam, D., \& Rucht, D. (1993). The cross-national diffusion of movement ideas. The Annals of the American Academy of Political and Social Science, 528, 56-74.

McAdam, D., Tarrow, S., \& Tilly, C. (2001). Dynamics of contention. New York: Cambridge University Press.

Merriman, R. B. ([1938] 1963). Six contemporaneous revolutions. Oxford: The Clarendon Press.

Meyer, J. W. (2010). World society, institutional theories, and the actor. Annual Review of Sociology, 36, 1-20.

Meyer, J. W., \& Jepperson, R. L. (2000). The 'actors' of modern society: the cultural construction of social agency. Sociological Theory, 18, 100-120.

Meyer, J. W., Boli, J., Thomas, G., \& Ramirez, F. (1997). World society and the nation-state. American Journal of Sociology, 103, 144-181.

Moghadam, V. (1997). Gender and revolutions. In J. Foran (Ed.), Theorizing revolutions (pp. 137-165). New York: Routledge.

Osa, M. (2003). Solidarity and contention: Networks of polish opposition. Minneapolis: University of Minnesota Press.

Paige, J. (1975). Agrarian revolution. New York: Free Press.

Palmer, R. R. (1959). The age of the democratic revolution. Princeton: Princeton University Press.

Parsa, M. (2000). States, ideologies and social revolutions: A comparative analysis of Iran, Nicaragua, and the Philippines. Cambridge: Cambridge University Press.

Pettee, G. S. (1938). The process of revolution. New York: Harper \& Row.

Pfaff, S. (2006). Exit-voice dynamics and the collapse of East Germany: The crisis of Leninism and the revolution of 1989. Durham: Duke University Press.

Pierson, P. (2003). Big, slow-moving, an ... invisible: Macrosocial processes in the study of comparative politics. In J. Mahoney \& D. Rueschemeyer (Eds.), Comparative historical analysis in the social sciences (pp. 177-207). New York: Cambridge University Press.

Ragin, C. (2008). Redesigning social inquiry: Fuzzy sets and beyond. Chicago: University of Chicago Press.

Rasler, K. (1996). Concessions, repression, and political protest in the Iranian revolution. American Sociological Review, 61, 132-152.

Reed, J.-P., \& Foran, J. (2002). Political cultures of opposition: exploring idioms, ideologies, and revolutionary agency in the case of Nicaragua. Critical Sociology, 28, 335-370. 
Schofer, E., Hironaka, A., Frank, D. J., \& Longhofer, W. (2012). Sociological institutionalism and world society. In E. Amenta, N. Kate, \& S. Alan (Eds.), The Wiley-Blackwell companion to political sociology (pp. 57-68). Hoboken: Wiley-Blackwell.

Selbin, E. (1993). Modern Latin American revolutions. Boulder: Westview.

Selbin, E. (2010). Revolution, rebellion, resistance: The power of story. London: Zed Books.

Sewell, W. H., Jr. (1985). Ideologies and social revolutions: reflections on the French case. The Journal of Modern History, 57, 57-85.

Sewell, W. H., Jr. (1994). A rhetoric of bourgeois revolution: The abbe Sieyes and what is the third estate? Durham: Duke University Press.

Sewell, W. H., Jr. (1996). Historical events as transformations of structures: inventing revolution at the bastille. Theory and Society, 25, 841-881.

Sharman, J. C. (2003). Culture, strategy, and state-centered explanations of revolution, 1789 and 1989. Social Science History, 27, 1-24.

Skocpol, T. (1979). States and social revolutions. Cambridge: Cambridge University Press.

Sohrabi, N. (1995). Historicizing revolutions: constitutional revolutions in the Ottoman Empire, Iran, and Russia, 1905-1908. American Journal of Sociology, 100, 1383-1447.

Sohrabi, N. (2002). Global waves, local actors: what the young Turks knew about other revolutions and why it mattered. Comparative Studies in Society and History, 44, 45-79.

Sohrabi, N. (2005). Revolutions as pathways to modernity. In A. Julia, E. S. Clemens, \& O. Ann Shola (Eds.), Remaking modernity (pp. 300-332). Durham: Duke University Press.

Strang, D., \& Meyer, J. W. (1993). Institutional conditions for diffusion. Theory and Society, 22, 487-511.

Strang, D., \& Tuma, N. B. (1993). Spatial and temporal heterogeneity in diffusion. American Journal of Sociology, 99, 614-639.

Tarrow, S. (1993). Cycles of collective action: between moments of madness and the repertoire of contention. Social Science History, 17, 281-307.

Tarrow, S. (2005). The new transnational activism. Cambridge: Cambridge University Press.

Tilly, C. (1978). From mobilization to revolution. New York: Random House.

Tilly, C. (1993). European revolutions, 1492-1992. Cambridge: Blackwell Publishers.

Tsutsui, K., \& Wotipka, C. M. (2004). Global civil society and the international human rights movement: citizen participation in human rights international nongovernmental organizations. Social Forces, 83, $587-620$.

Union of International Associations. (2011). Yearbook of international organizations. Munich: Union of International Associations and K G Saur Verlag.

United Nations Population Division. (2010). World population prospects, the 2010 revision. New York: United Nations.

Urdal, H. (2006). A clash of generations? Youth bulges and political violence. International Studies Quarterly, $50,607-629$.

Viterna, J. (2006). Pulled, pushed and persuaded: explaining women's mobilization into the Salvadoran guerilla army. American Journal of Sociology, 112, 1-45.

Wallerstein, I. (1980). The modern world system II: Mercantilism and the consolidation of the European world economy. San Diego: Academic.

Walt, S. (1996). Revolution and war. Ithaca: Cornell University Press.

Walton, J. (1984). Reluctant rebels: Comparative studies of revolution and underdevelopment. New York: Columbia University Press.

Weyland, K. (2009). The diffusion of revolution: '1848' in Europe and Latin America. International Organization, 63, 391-423.

Wickham-Crowley, T. (1992). Guerillas and revolution in Latin America. Princeton: Princeton University Press.

World Bank. (2013). World development indicators. Washington: The World Ban.

Colin J. Beck is Assistant Professor of Sociology at Pomona College. His primary areas of interest are revolutions and political violence, examined through comparative-historical and quantitative approaches. Currently, he is researching the use of comparative methods in the study of revolution and the empirical basis of the field's knowledge. Previous work has been published in Social Forces, Social Science History, and Mobilization among other journals, and his book Radicals, Revolutionaries, and Terrorists is under contract with Polity Press. 